\title{
RNA detection with high specificity and sensitivity using nested fluorogenic Mango NASBA
}

\author{
AMIR ABDOLAHZADEH, ELENA V. DOLGOSHEINA, and PETER J. UNRAU \\ Department of Molecular Biology and Biochemistry, Simon Fraser University, Burnaby, British Columbia V5A 1S6, Canada
}

\begin{abstract}
There is a pressing need for nucleic acid-based assays that are capable of rapidly and reliably detecting pathogenic organisms. Many of the techniques available for the detection of pathogenic RNA possess one or more limiting factors that make the detection of low-copy RNA challenging. Although RT-PCR is the most commonly used method for detecting pathogenrelated RNA, it requires expensive thermocycling equipment and is comparatively slow. Isothermal methods promise procedural simplicity but have traditionally suffered from amplification artifacts that tend to preclude easy identification of target nucleic acids. Recently, the isothermal SHERLOCK system overcame this problem by using CRISPR to distinguish amplified target sequences from artifactual background signal. However, this system comes at the cost of introducing considerable enzymatic complexity and a corresponding increase in total assay time. Therefore, simpler and less expensive strategies are highly desirable. Here, we demonstrate that by nesting NASBA primers and modifying the NASBA inner primers to encode an RNA Mango aptamer sequence we can dramatically increase the sensitivity of NASBA to 1.5 RNA molecules per microliter. As this isothermal nucleic acid detection scheme directly produces a fluorescent reporter, real-time detection is intrinsic to the assay. Nested Mango NASBA is highly specific and, in contrast to existing RNA detection systems, offers a cheap, simple, and specific way to rapidly detect single-molecule amounts of pathogenic RNA.
\end{abstract}

Keywords: RNA; Mango; TO1 fluorophore; isothermal amplification; nucleic acid detection; nested NASBA; singlemolecule detection

\section{INTRODUCTION}

Pathogens, such as viruses, bacteria, and eukaryotic parasites, are among the most serious sources of public health concerns worldwide (Law et al. 2015). Successful methods for disease diagnosis and treatment, food safety control, and environmental monitoring, therefore, require rapid and specific identification of infectious agents (Zhao et al. 2014; Law et al. 2015). Simplicity and low cost are equally important. For example, methods that do not rely on highend instrumentation and skilled personnel can be used in settings where measles, influenza, HIV and Ebola viruses, malaria, gonorrhea, and salmonella-based food poisoning pose human health risks. By using these methods, their diagnosis could be facilitated when advanced diagnostic technologies are limited or nonexistent because of economic constraints (Niemz et al. 2011; Wang et al. 2016). Despite the tremendous efforts that have been made in biochemical engineering and nanotechnology, few pathogen detection methods currently meet all five criteria of affordability, sensitivity, specificity, rapidity, and robustness.

Corresponding author: punrau@sfu.ca

Article is online at http://www.rnajournal.org/cgi/doi/10.1261/rna. 072629.119.
Traditional methods for bacterial detection involve culturing of organisms on agar plates and are laborious and time-consuming. They typically require 2-3 $d$ of culturing and more than a week for the identification to be confirmed, greatly slowing the rate of effective diagnosis (Zhao et al. 2014; Law et al. 2015). Misdiagnosis is significant, and inappropriate therapies have been shown to reduce survival for serious infections by fivefold (Craw and Balachandran 2012). Significantly, culture methods can only identify organisms that are capable of growing on culture and thus fail to identify viable but unculturable pathogens (Ramamurthy et al. 2014; Law et al. 2015). These problems can be overcome by nucleic acid testing (NAT) methodologies, which fundamentally involve three steps: nucleic acid isolation, amplification, and detection. NAT methods are extensively used for pathogen detection (Niemz et al. 2011; Zhao et al. 2014; Law et al. 2015). Between DNA and RNA, RNA detection is of particular interest, as many pathogens express higher initial template

(C) 2019 Abdolahzadeh et al. This article is distributed exclusively by the RNA Society for the first 12 months after the full-issue publication date (see http://rnajournal.cshlp.org/site/misc/terms.xhtml). After 12 months, it is available under a Creative Commons License (Attribution-NonCommercial 4.0 International), as described at http:// creativecommons.org/licenses/by-nc/4.0/. 
concentrations of RNA suitable for amplification or, in the case of RNA viruses, utilize it as their sole genetic information. NAT is intrinsically more specific and sensitive than conventional methods and allows the routine identification of pathogens without culturing, significantly shortening detection times.

Polymerase chain reaction (PCR) was the first such method and remains the most popular amplification technology for detecting low-abundance nucleic acids. Invented nearly 30 years ago (Saiki et al. 1985), it is capable of detecting a specific target DNA sequence corresponding to a single bacterial pathogen (Lazcka et al. 2007; Velusamy et al. 2010). The PCR amplification products are traditionally visualized using gel electrophoresis and nucleic acid intercalating fluorescent dyes. PCR variations include multiplex PCR (mPCR) and real-time or quantitative PCR (qPCR) (Higuchi et al. 1993). In comparison to traditional PCR, qPCR does not require gel electrophoresis for detection, as it monitors product formation in real time by measuring fluorescence produced by intercalating dyes (such as SYBR Green), dual labeled probes (TaqMan), or molecular beacons (Navarro et al. 2015). For RNA-based detection, RTPCR is used: RNA is first reverse-transcribed into cDNA, which is then amplified by PCR (Nolan et al. 2006), adding significantly to assay time and complexity. Although highly sensitive and specific, PCR and RT-PCR methods remain costly because of the need for expensive thermocycling equipment.

Isothermal amplification of nucleic acids is an alternative to PCR and RT-PCR. In these methods, amplification is achieved at a constant temperature without the need for thermocycling, making it both less complex and less expensive (Compton 1991; Notomi et al. 2000; Vincent et al. 2004; Piepenburg et al. 2006; Ali et al. 2014; Zhao et al. 2015). Isothermal methods are simpler and cheaper to implement, as they need only a fixed temperature incubation device. Nucleic acid sequence-based amplification (NASBA) is one such technique. It uses three enzymes and two primers to exponentially amplify RNA target strands (Compton 1991). The first primer serves as the initial reverse-transcription primer, which simultaneously serves to add a T7 promoter to the resulting cDNA (Primer PA; Fig. 1A). After cDNA synthesis, the RNA in the newly formed heteroduplex is degraded by RNase $H$ allowing the second DNA primer to hybridize (Primer PB; Fig. 1A), resulting in a dsDNA after extension by reverse transcriptase (RT). This dsDNA can then be transcribed by T7 RNA polymerase. As the resulting RNA can in turn be reverse-transcribed, exponential amplification occurs.

Nevertheless, amplifying very low concentrations of nucleic acid presents the increased possibility for nonspecific primer hybridization allowing for the amplification of incorrect products. Recently SHERLOCK was developed to address this problem by using a second CRISPR-mediated step to effectively screen the products of isothermal ampli-

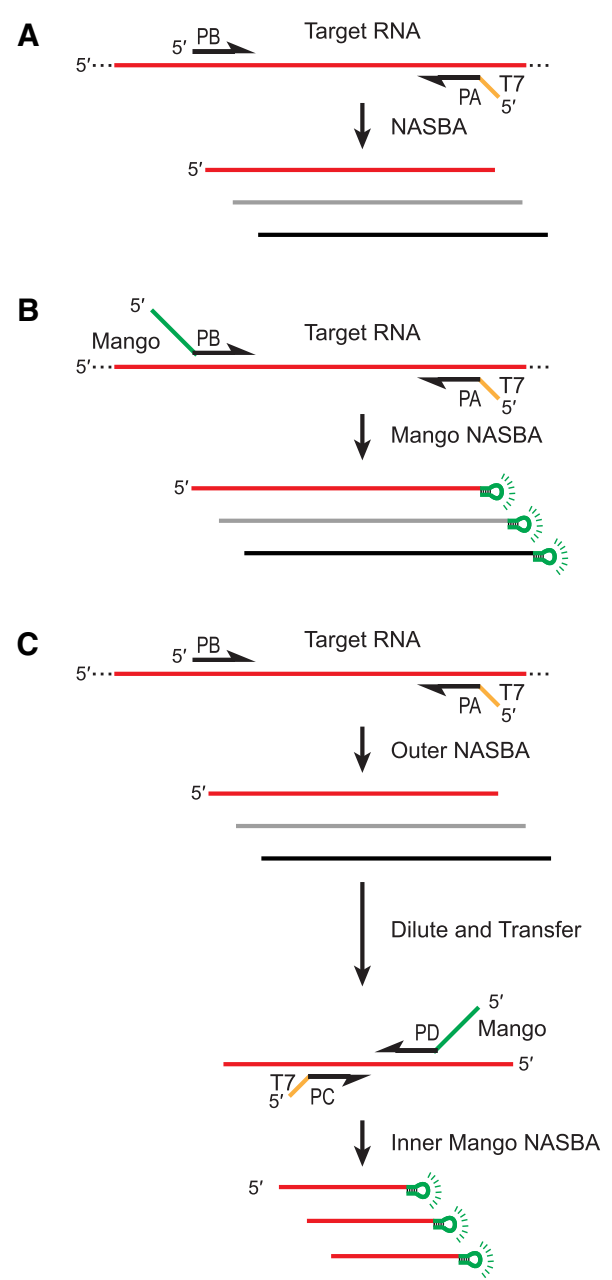

FIGURE 1. Insertion of RNA Mango aptamers into RNA NASBA. (A) Traditional NASBA uses two primers to produce an RNA product. Artifacts are also commonly produced when amplified by primers PA and PB and are indicated by black and gray products. (B) Mango NASBA system features the addition of a Mango aptamer template sequence on $\mathrm{PB}$ primer, resulting in the production of an RNA product containing a fluorescent Mango tag after T7 transcription, also sensitive to artifacts. (C) Nested Mango NASBA features an outer primer NASBA reaction whose products are then diluted and fed into a second inner Mango NASBA reaction, reducing artifactual amplification of products.

fication (RPA was demonstrated) for template specific amplification products (Gootenberg et al. 2017, 2018). This additional validation step allows the artifactual background of the preceding isothermal step to be selectively overcome. Although having an impressive sensitivity down to the aM level and although it enables SNP-based specificity, SHERLOCK-based detection requires a total of six enzymes (reverse transcriptase, RPA: recombinase/polymerase/strand displacement proteins, T7 RNA polymerase, and Cas13a). This, together with a requirement for a synthetic fluorescent reporter construct, adds significant complexity to the method. 
Fluorogenic RNA aptamers offer an exciting opportunity to report the successful amplification of target RNA sequences. Although they have been previously used to monitor the course of a transcription in vitro by producing a fluorescent signal (Sando et al. 2008; Höfer et al. 2013; Autour et al. 2016; Alam et al. 2019; Shi et al. 2019), coupling their synthesis to the amplification provided by an isothermal assay has, to our knowledge, not been described prior. The RNA Mango aptamer series has nanomolar binding affinity to a thiazole orange-based ligand (TO1-Biotin) and enhances the brightness of the fluorogenic ligand up to 4000 times upon binding, which makes them useful in vitro fluorescent reporters (Dolgosheina et al. 2014; Dolgosheina and Unrau 2016; Autour et al. 2018). Of particular note, the second generation of RNA Mango aptamers (Mango II, III, and IV) are highly resistant to the magnesium concentrations and work in a broad range of monovalent metal ion concentrations that are typically found in in vitro assays (Autour et al. 2018; Trachman et al. 2019).

Here, by nesting NASBA primers and modifying the inner set of NASBA primers to encode a fluorogenic aptamer, we demonstrate that we can detect attoMolar $(\mathrm{aM}, 1.5$ RNA molecules per $\mu \mathrm{L}$ ) concentrations of RNA template. In the absence of nesting, we show that Mango NASBA (Fig. 1B) has a sensitivity in the picoMolar (pM) template range but such an unnested method is highly susceptible to background amplification artifacts. Nested Mango NASBA (NMN, Fig. 1C; Supplemental Fig. S1) in contrast is much more robust and even in the presence of significant amounts of competitor template can reliably detect low concentrations of RNA template.

\section{RESULTS AND DISCUSSION}

\section{Sensitivity of Mango NASBA}

We modified previously published NASBA primers for Escherichia coli ClpB (Heijnen and Medema 2009) to include a Mango III sequence variant allowing us to detect $\sim 25 \mathrm{pM}\left(1.5 \times 10^{7} \mathrm{RNA} / \mu \mathrm{L}\right)$ of E. coli ClpB RNA template. However, detection was hampered by a high artifactual background fluorescent signal that amplified rapidly even in the complete absence of RNA template and allowed only a twofold distinction between background and signal (primers P1/P2A; Table 1; Fig. 2A; Supplemental Fig. S2). This relatively poor intrinsic sensitivity was not primer- nor template-specific, as Pseudomonas fluorescens ClpB reverse-complement RNA template could be detected with similar sensitivity using primers designed to hybridize a shorter distance apart than for the E. coli ClpB target. Although these primers had considerably less intrinsic background fluorescence signal, they too could only demonstrate an RNA detection sensitivity of pM (primers P7/P8; Table 1; Supplemental Fig. S3). To explore the source of the artifactual signal found with the E. coli primers, RNA
TABLE 1. Sequences of primers and targets

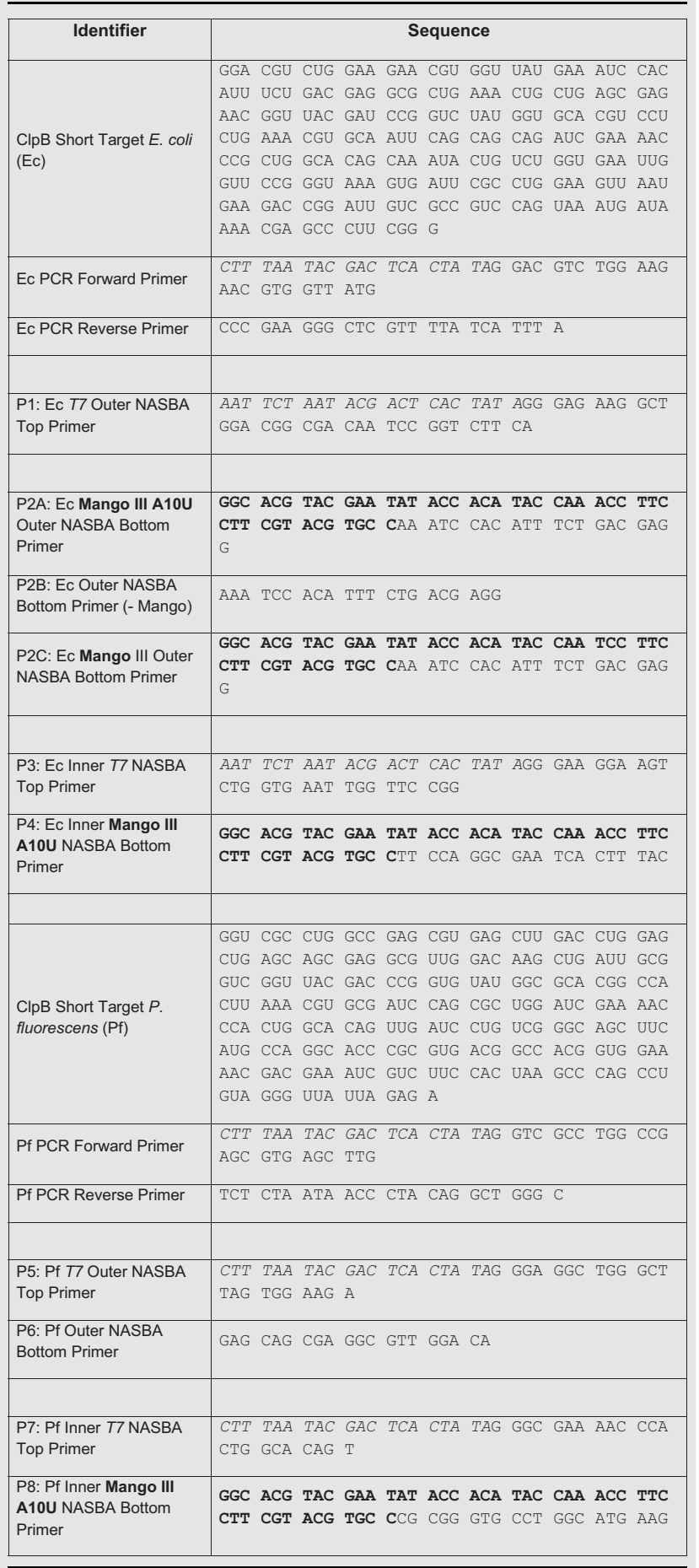

Sequence in bold corresponds to bolded identifier information.

products were analyzed after $2 \mathrm{~h}$ of NASBA incubation in a denaturing gel. Small RNA products were produced for all template concentrations between 0 and $25 \mathrm{fM}$ as judged by TO1-Biotin gel staining (Supplemental Fig. S4A). These gel results suggest that primer mishybridization results 


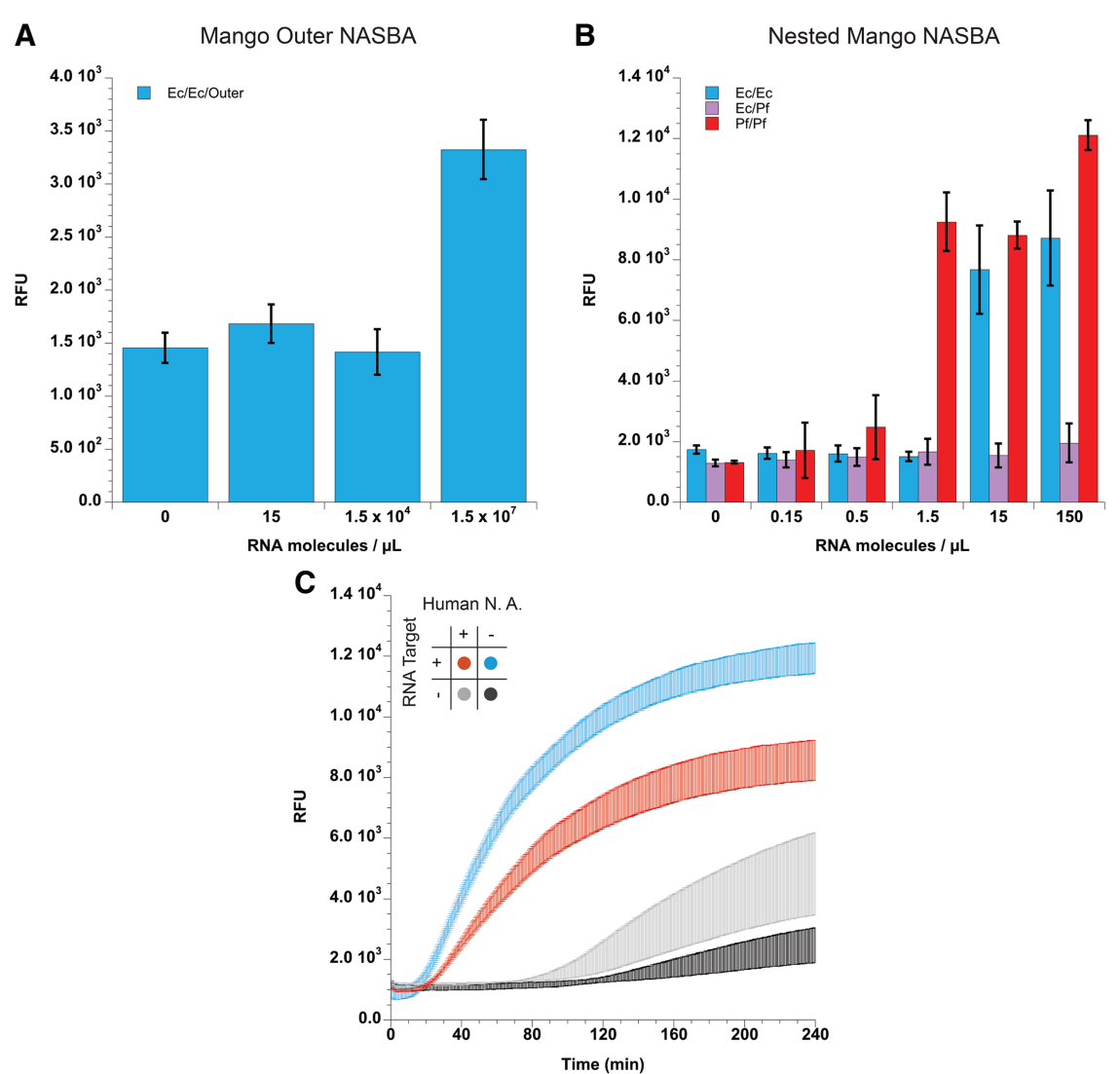

FIGURE 2. Nested Mango NASBA is sensitive and specific to target RNA sequence and is robust even when an unrelated nucleic acid sample is added. (A) Unnested outer ( $E$. coli $C / p B$ RNA, E. coli primers P1/P2A) sensitivity. (B) Nested RNA Mango dramatically improves sensitivity. E. coli primers (P1/P2B and P3/P4) with E. coli ClpB RNA (Ec/Ec) and is shown in blue. Using the same E. coli primers, P. fluorescens ClpB RNA was added (Ec/Pf) instead of $E$. coli; target is shown in purple. P. fluorescens primers (P5/P6 and P7/P8) with $P$. fluorescens ClpB RNA (Pf/Pf) is shown in red. (C) Nested Mango NASBA using E. coli primers as in panel $B$ was performed with the inner NASBA time courses shown. (Blue) $150 \mathrm{E}$. coli target molecules $/ \mu \mathrm{L}$, (red) $150 \mathrm{E}$. coli target molecules $/ \mu \mathrm{L}$ in the presence of $5 \mathrm{ng} / \mu \mathrm{L}$ of A549 Human Lung Carcinoma total nucleic acid, (black) no template added, (gray) $5 \mathrm{ng} / \mu \mathrm{L}$ of A549 Human Lung Carcinoma cell total nucleic acid. Error bars reflect the standard deviation of three replicates for all panels.

in transcriptional artifacts able to produce short Mango aptamer containing RNA. Although such artifacts could in principle be avoided by careful primer design, based on these results the intrinsic sensitivity of Mango NASBA remains highly limited for the detection of target RNAs at concentrations lower than $\mathrm{pM}$. As similar problems are observed during PCR amplification of low-copy-number templates and because nesting PCR primers is a viable solution, we decided to test the nesting of NASBA primers (Fig 1C; Supplemental Fig. S1), which to our knowledge, has not been previously implemented.

\section{Sensitivity and specificity of nested Mango NASBA}

Analogous to nested PCR, nesting NASBA primers avoids artifacts by selectively amplifying only RNA sequences that are recognized by not one set of primers, but by two (outer: PA/PB; inner: PC/PD; Fig. 1C). To optimize the transition to the inner primer NASBA reaction, we first tested how little NASBA primer is needed to result in isothermal amplification, based on the hypothesis that dilution below this concentration would preclude the activity of the outer primers in the inner NASBA reaction. Using an E. coli template concentration of 25 $\mathrm{pM}$, it was observed that primer concentrations of $<5 \mathrm{nM}$ resulted in negligible amplification product even after $120 \mathrm{~min}$ (Supplemental Fig. S4B). Therefore, we decided that after quenching the outer NASBA reaction by the addition of EDTA, we would dilute the stopped reaction 100-fold into the inner NASBA reaction, as our NASBA primer concentrations are used at a concentration of $250 \mathrm{nM}$.

In our first test of NMN, we used $E$. coli outer primers lacking the Mango tag but otherwise identical in sequence to those used in the previously discussed Mango NASBA (P1/P2B; Table 1). The outer NASBA reaction was incubated for $40 \mathrm{~min}$ at $41^{\circ} \mathrm{C}$. We then diluted this EDTA quenched outer reaction 100-fold into an inner NASBA reaction in which nested inner NASBA Mango primers designed to contain a Mango III tag were now added (P3/P4; Table 1). In contrast to unnested Mango NASBA, in which amplification artifacts emerged even in the zero template control, we could now easily detect $25 \mathrm{aM}(15 \mathrm{RNA} / \mu \mathrm{L})(\mathrm{Ec} / \mathrm{Ec}, \mathrm{Fig} .2 \mathrm{~B})$. Even though the outer primers were presumably not optimal in design, nesting these primers with inner Mango NASBA primers provided a more than six orders of magnitude increase in sensitivity. Examining the time-dependent emergence of the inner Mango NASBA fluorescence indicated that a robust time-dependent signal emerged in $<60 \mathrm{~min}$ of incubation (Supplemental Fig. S5), indicating that NMN can be performed in as little as $100 \mathrm{~min}$.

Using this NMN strategy we then designed a NMN $P$. fluorescens primer set. A new outer primer pair was designed while we utilized the previously designed outer Mango NASBA primers as the inner primer pair RNA (outer: P5/P6; inner: P7/P8 Table 1). Here we could detect 2.5 aM (1.5 RNA/ $\mu \mathrm{L})$ of $P$. fluorescens ClpB target (Pf/Pf, Fig. 2B; Supplemental Fig. S5). These P. fluorescens primers 
yielded higher sensitivity, possibly because of the more stringent design rules we used to minimalize both primer dimerization and primer self-extension. Specifically, we designed the $3^{\prime}$ ends of each primer so as to preclude hybridization to either itself or its partner by any more than $3 \mathrm{nt}$ where possible. Nesting NASBA primers, together with these simple design constraints, sensitivity dramatically increased by eight orders of magnitude relative to the unnested Mango NASBA (Supplemental Fig. S3).

The E. coli and $P$. fluorescens $C l p B$ templates tested here differ by $78 \mathrm{nt}$ in the nested primer binding sequence region, 65 nt of which are in primer hybridization regions (see alignment in Supplemental Fig. S6). When the NMN primers used to target $E$. coli $C l p B$ were used against the $P$. fluorescens target, fluorescence remained within the same error as the $0 \mathrm{RNA} / \mu \mathrm{L}$ reaction control for all ranges of template concentrations tested (Ec/Pf; Fig. 2B; Supplemental Fig. S5). This suggests that even nonoptimal primers, when used in a nested fashion, can be specific for their targets and do not suffer from the artifactual amplification products we had observed in unnested NASBA.

To further explore the specificity of NMN, a large amount of human total nucleic acid was mixed with a low concentration of E. coli ClpB template. E. coli ClpB RNA target was mixed with or without an excess of human total nucleic acid (150 RNA molecules/ $\mu \mathrm{L}$ final $E$. coli $C / p B, 5 \mathrm{ng} / \mu \mathrm{L}$ human total nucleic acid) and NMN was performed using the Ec primers (Fig 2C; outer: P1/P2B; inner: P3/P4; Table 1). Although this amount of human nucleic acid definitely had an effect, decreasing the amplification of the $E$. coli positive signal and enhancing the emergence of the negative template sample, the assay was still remarkably robust and was able to detect the specific $E$. coli target in $\sim 80$ min of total inner and outer reaction time, as signal was clearly differentiated from the negative controls after as little as 40 min of inner Mango NASBA incubation.

To further test the applicability of NMN, we explored the ability of the system to detect $E$. coli cells in human tissue culture. Exponentially growing cells were quantified by $\mathrm{OD}$, pelleted, and then added to $50 \mu \mathrm{L}$ of depleted tissue culture media. Using a standard RNA column purification kit, serial dilution of this sample allowed us to detect by NMN (Table 1; outer primer: P1/P2B; inner primer: P3/ P4; Supplemental Fig. S7) what we calculate to be the equivalent of 32 to 1000 cells of E. coli. As expected, amplification artifacts from the outer reactions were observed, with amplification products visible by SYBR Safe in the highest bacterial concentrations tested (Supplemental Fig. S8A). After a longer $4 \mathrm{~h}$ inner Mango NASBA amplification, so as to maximize the accumulation of possible artifacts, the resultant RNA products were loaded into denaturing gels and stained with either TO1-Biotin (to visualize Mango containing RNA transcripts) or SYBR Safe (to visualize total RNA transcribed). In contrast to the outer NASBA products, the inner RNA products show the ex- pected RNA size when stained with TO1-Biotin, down to the 32- to 1000-cell concentration range, at which point a smaller product was also formed that was present in the depleted media negative control lane (Supplemental Figure S8B). Staining the inner NASBA RNA products with SYBR Safe indicated that in addition to these minor artifactual species, other RNAs had been produced that were both longer and shorter (Supplemental Fig. S7C); however, these bands did not encode a Mango tag as they were not observed to be significantly stained in the TO1-Biotin gel.

The ability to detect aM concentrations of RNA using NMN in a fashion that is intrinsically resistant to the presence of high levels of competing nucleic acids makes this assay generally useful as it can detect single molecules. New technologies, such as SHERLOCK, also report 2 aM sensitivity (Gootenberg et al. 2017). Comparatively, NMN was able to reliably detect a concentration of $2.5 \mathrm{aM}$ or 1.5 RNA molecules per $\mu \mathrm{L}$ of reaction. Notably in this regard, at very low concentrations of template the large error bars we observe for $0.15 \mathrm{~mol} / \mu \mathrm{L}$ (three molecules in this $20 \mu \mathrm{L}$ reaction) and $0.5 \mathrm{~mol} / \mu \mathrm{L}$ (10 molecules per reaction) $P$. fluorescens time series (Supplemental Fig. S5) result from averaging a very digital all-or-nothing response in the triplicate data (Supplemental Fig. S9). Therefore, we are perhaps being conservative in setting our limits of detection, which may in actuality be lower than stated here, but that would require more precise methods of single-molecule analysis to fully resolve.

Although these systems are both very sensitive to RNA detection, NMN can be performed using only a reverse transcriptase, RNase $\mathrm{H}$, and T7 RNA polymerase (three enzymes) in two simple sequential reactions that differ only in primer composition and that provide real-time detection by the addition of commercially available TO1-Biotin fluorophore. This may well make NMN more robust than SHERLOCK, which by comparison requires the use of a reverse transcriptase, a three-enzyme isothermal amplification system (RPA), T7 RNA polymerase, and a Cas13a (six enzymes total) along with a cleavable fluorescent reporter (Gootenberg et al. 2017). However, SHERLOCK, with orthogonal CRISPR enzymes, can be multiplexed for the detection of multiple targets and can be performed in a single reaction tube (Gootenberg et al. 2018). Although NMN has not been demonstrated in a multiplexed form at this time, it appears entirely possible that given the high ligand specificity of the Mango aptamer (Jeng et al. 2016), NMN multiplexing will be possible in the future via the generation of orthogonal RNA aptamers for same tube multiplexing. Further, it is also entirely possible to multiplex by first performing an outer Mango NASBA reaction across a conserved region of RNA that contains variable interior sequence regions. Parallel inner NASBA reactions could then be run to identify individual sequence variants. Work using NMN should ideally be performed in a clean and 
sterile environment to prevent cross-contamination during transfer from the outer reaction into the inner reaction (a common point of care for nested PCR, as the tube containing amplified target must be opened for transfer).

In conclusion, the Mango NASBA approach offers a simple real-time method for the fluorescent method for detection of RNA. By nesting NASBA and achieving a real-time readout with Mango aptamers, NMN displays dramatically improved sensitivity capable of single-molecule detection as demonstrated here. NMN has high specificity and allows for detection of target RNA even in the presence of a large background of nucleic acid. As the inner and outer reactions used in NMN are identical except for their primer composition, the system remains minimally complex, making such assays highly scalable.

\section{MATERIALS AND METHODS}

\section{ClpB target RNA generation}

ClpB DNA template was first generated by colony PCR reactions performed by picking either $E$. coli (strain $\mathrm{DH} 5 \alpha$ ) or $P$. fluorescens (strain ATCC 13525) colonies directly into PCR reactions consisting of Taq (NEB, $1 \mathrm{U} / 10 \mu \mathrm{L}$ final), $0.2 \mathrm{mM}$ each dNTP, $10 \mathrm{mM}$ TRIS buffer $\mathrm{pH} 8.3,50 \mathrm{mM} \mathrm{KCl}, 1.5 \mathrm{mM} \mathrm{MgCl}_{2}$, and $0.01 \%$ gelatin and the relevant primers (IDT) from Table 1. The resulting DNA was cloned into a pGEM-T Easy Vector (Promega) and sequences confirmed by Eurofins tube sequencing. Using plasmid as template, PCR reactions were then carried out and followed by ethanol precipitation in $300 \mathrm{mM} \mathrm{NaCl}$ and $70 \%$ ethanol. Pellets were resuspended in water to generate a 10× DNA template stock. Transcriptions were carried out using $2 \times$ template, T7 RNA polymerase (Applied Biological Materials), in $8 \mathrm{mM}$ GTP, $5 \mathrm{mM}$ CTP and ATP, 2 mM UTP, $40 \mathrm{mM}$ Tris buffer $\mathrm{pH} 7.9,2.5 \mathrm{mM}$ spermidine, $26 \mathrm{mM} \mathrm{MgCl}_{2}$, and $0.01 \%$ Triton X-100. RNA was purified via 5\% PAGE (19:1 Acrylamide:bis). The resolved RNA band excised and placed on a rotator overnight in $300 \mathrm{mM} \mathrm{NaCl}$, before recovery by ethanol precipitation and resuspension in water. Concentrations were determined using a SHIMADZU dual beam spectrophotometer and IDT's on-line nearest neighbor estimate for extinction coefficient.

\section{Mango NASBA}

NASBA primers (IDT) were designed to target RNA amplification to the $E$. coli or $P$. fluorescens $C / p B$ mRNA templates generated above (shown as "ClpB short target $E$. coli" and "ClpB short target P. fluorescens," respectively, Table 1; Supplemental Fig. S6). Reactions were carried out using NASBA buffer mix (Life Sciences, NECB-1-24), nucleotide mix (Life Sciences, NECN-124), $250 \mathrm{nM}$ of each primer described in the text, $480 \mathrm{nM}$ TO1Biotin (Applied Biological Materials), and NASBA enzyme mix (Life Sciences, NEC-1-24) mixed to a final volume of $14 \mu \mathrm{L}$. NASBA reactions were mixed excluding the enzyme mix and RNA target. RNA template was heated for $2 \mathrm{~min}$ to $65^{\circ} \mathrm{C}$ and brought down for $5 \mathrm{~min}$ to $41^{\circ} \mathrm{C}$ in a $\mathrm{MJ}$ research PTC- 100 thermocycler before adding $1 \mu \mathrm{L}$ of the template to each reaction mix (final template concentrations of either 0, 25 aM, $25 \mathrm{fM}$, $25 \mathrm{pM})$. To initiate the reaction, $5 \mu \mathrm{L}$ of enzyme mix was added to the reactions and mixed. Reaction tubes were then sealed and incubated at $41^{\circ} \mathrm{C}$ in eight-tube strips with optical caps (Applied Biosystems, catalog \# 4358293, 4323032) on a StepOne Real-Time PCR System (Applied Biosystems). This instrument was set to read SYBR Green reagent in the following program: (i) Ramp to $41^{\circ} \mathrm{C}$, read; (ii) hold for $30 \mathrm{sec}$ at $41^{\circ} \mathrm{C}$, read; and (iii) repeat step 2 until 480 cycles complete. Experiments shown in Supplemental Figure S4 were carried out with primer P2C (Table 1) using the WT Mango III that did not carry the A10U mutation. This mutation is known to make Mango III 14\% brighter (Trachman et al. 2019).

\section{Nested Mango NASBA}

Outer amplification reactions were performed as just described above and using the primers in the Results and Discussion. Outer reactions were stopped at $40 \mathrm{~min}$ by the addition of $5 \mu \mathrm{L}$ of $50 \mathrm{mM}$ EDTA to a final concentration of $10 \mathrm{mM}$ and flash frozen in either liquid nitrogen or ethanol on dry ice. After thawing, $5 \mu \mathrm{L}$

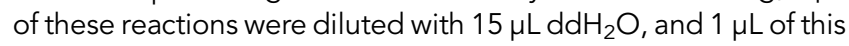
dilution was promptly added into the inner-nested Mango NASBA reactions for a net 100 -fold dilution. The inner primers are as described in the text (Table 1). Reactions were monitored for fluorescence of TO1-Biotin in real time again using the StepOne Real-Time PCR System and settings as just described.

\section{Detection of E. coli RNA in the presence of human nucleic acid}

Total human nucleic acid was extracted from A549 Human Lung Carcinoma cells via phenol-chloroform extraction and concentrations were measured on a NanoDrop 2000 by OD. Reactions were performed as above; however, reactions either had $150 \mathrm{E}$. coli target molecules $/ \mu \mathrm{L}$ or not, with $5 \mathrm{ng} / \mu \mathrm{L}$ of $\mathrm{A} 549$ human lung carcinoma cell total nucleic acid or not.

\section{Detection of $E$. coli in the presence of conditioned mammalian cell culture media}

To test the validity of the use of nested Mango NASBA, LB media was inoculated with $E$. coli and concentration was monitored by absorbance at $600 \mathrm{~nm}$ (cell number calculated using Agilent online tool; $\mathrm{OD}_{600}=0.5$ implying $4 \times 10^{8} \mathrm{cells} / \mathrm{mL}$ ). An aliquot of $10^{8}$ cells exposed to a heat shock for $10 \mathrm{~min}$ at $41^{\circ} \mathrm{C}$ to induce ClpB RNA was then promptly pelleted at $4000 \mathrm{~g}$ for $4 \mathrm{~min}$. The cell pellet was resuspended in $50 \mu \mathrm{L}$ of depleted cell culture media (MCF7 waste media generated during cell passaging) and incubated further for $3 \mathrm{~min}$ at $41^{\circ} \mathrm{C}$. Samples were pelleted for $4 \mathrm{~min}$ at $4000 \mathrm{~g}$ before subject to a Nucleospin RNA kit (Macherey-Nagel) using their recommended protocol with the exceptions of avoiding the DNase step and performing elution using 2 mM EDTA. Total nucleic acid samples were used for nested Mango NASBA reactions as described above. A negative control sample for NMN was an extraction of nucleic acid from depleted media containing no $E$. coli cells treated to the same extraction procedure. 


\section{PAGE Mango visualization}

Samples to be visualized on PAGE were mixed with three volumes formamide supplemented with $20 \mathrm{mM}$ EDTA and then heated for $5 \mathrm{~min}$ to $90^{\circ} \mathrm{C}$. Samples were then loaded and run into $8 \%$ PAGE (19:1 Acrylamide:bis). Post staining of the gels was performed using $100 \mathrm{~mL}$ of $1 \times W B(140 \mathrm{mM} \mathrm{KCl}, 1 \mathrm{mM} \mathrm{MgCl}, 10 \mathrm{mM}$ $\mathrm{NaH}_{2} \mathrm{PO}_{4} \mathrm{pH} 7.2,0.05 \%$ Tween-20) supplemented with $20 \mathrm{nM}$ TO1-Biotin, and Mango NASBA bands were imaged on a GE Al600RGB imager as described elsewhere (Yaseen et al. 2019). Alternatively, gels were stained with $1 \times$ SYBR Safe stain otherwise under the same conditions.

\section{Sequence alignment}

Sequences were aligned using Geneious software and aligned using the Clustal method (Geneious version 11.0 created by Biomatters; available from https://www.geneious.com).

\section{SUPPLEMENTAL MATERIAL}

Supplemental material is available for this article.

\section{ACKNOWLEDGMENTS}

This work was supported by a Natural Sciences and Engineering Research Council (NSERC) operating grant to P.J.U. and a NSERC Collaborative Research and Development (CRD) industrial collaborative grant to P.J.U. and Applied Biological Materials.

Received July 11, 2019; accepted September 16, 2019.

\section{REFERENCES}

Alam KK, Jung JK, Verosloff MS, Clauer PR, Lee JW, Capdevila DA, Pastén PA, Giedroc DP, Collins JJ, Lucks JB. 2019. Rapid, lowcost detection of water contaminants using regulated in vitro transcription. Synth Biol. doi:10.1101/619296

Ali MM, Li F, Zhang Z, Zhang K, Kang D-K, Ankrum JA, Le XC, Zhao W. 2014. Rolling circle amplification: a versatile tool for chemical biology, materials science and medicine. Chem Soc Rev 43: 3324 3341. doi:10.1039/c3cs60439j

Autour A, Westhof E, Ryckelynck M. 2016. iSpinach: a fluorogenic RNA aptamer optimized for in vitro applications. Nucleic Acids Res 44: 2491-2500. doi:10.1093/nar/gkw083

Autour A, Jeng SCY, Cawte AD, Abdolahzadeh A, Galli A Panchapakesan SSS, Rueda D, Ryckelynck M, Unrau PJ. 2018. Fluorogenic RNA Mango aptamers for imaging small non-coding RNAs in mammalian cells. Nat Commun 9: 656. doi:10.1038/ s41467-018-02993-8

Compton J. 1991. Nucleic acid sequence-based amplification. Nature 350: 91-92. doi:10.1038/350091a0

Craw P, Balachandran W. 2012. Isothermal nucleic acid amplification technologies for point-of-care diagnostics: a critical review. Lab Chip 12: 2469-2486. doi:10.1039/c2lc40100b

Dolgosheina EV, Unrau PJ. 2016. Fluorophore-binding RNA aptamers and their applications. Wiley Interdiscip Rev RNA 7: 843-851. doi:10.1002/wrna.1383

Dolgosheina EV, Jeng SCY, Panchapakesan SSS, Cojocaru R, Chen PSK, Wilson PD, Hawkins N, Wiggins PA, Unrau PJ. 2014. RNA mango aptamer-fluorophore: a bright, high-affinity complex for RNA labeling and tracking. ACS Chem Biol 9: 2412-2420. doi:10.1021/cb500499x

Gootenberg JS, Abudayyeh OO, Lee JW, Essletzbichler P, Dy AJ, Joung J, Verdine V, Donghia N, Daringer NM, Freije CA, et al. 2017. Nucleic acid detection with CRISPR-Cas13a/C2c2. Science 356: 438-442. doi:10.1126/science.aam9321

Gootenberg JS, Abudayyeh OO, Kellner MJ, Joung J, Collins JJ, Zhang F. 2018. Multiplexed and portable nucleic acid detection platform with Cas13, Cas12a, and Csm6. Science 360: 439-444. doi:10.1126/science.aaq0179

Heijnen L, Medema G. 2009. Method for rapid detection of viable Escherichia coli in water using real-time NASBA. Water Res 43: 3124-3132. doi:10.1016/j.watres.2009.04.025

Higuchi R, Fockler C, Dollinger G, Watson R. 1993. Kinetic PCR analysis: real-time monitoring of DNA amplification reactions. Biotechnology 11: 1026. doi:10.1038/nbt0993-1026

Höfer K, Langejürgen LV, Jäschke A. 2013. Universal aptamer-based real-time monitoring of enzymatic RNA synthesis. J Am Chem Soc 135: 13692-13694. doi:10.1021/ja407142f

Jeng SCY, Chan HHY, Booy EP, McKenna SA, Unrau PJ. 2016. Fluorophore ligand binding and complex stabilization of the RNA Mango and RNA Spinach aptamers. RNA 22: 1884-1892. doi:10.1261/rna.056226.116

Law JW-F, Ab Mutalib N-S, Chan K-G, Lee L-H. 2015. Rapid methods for the detection of foodborne bacterial pathogens: principles, applications, advantages and limitations. Front Microbiol 5: 770.

Lazcka O, Campo FJD, Muñoz FX. 2007. Pathogen detection: a perspective of traditional methods and biosensors. Biosens Bioelectron 22: 1205-1217. doi:10.1016/j.bios.2006.06.036

Navarro E, Serrano-Heras G, Castaño MJ, Solera J. 2015. Real-time PCR detection chemistry. Clin Chim Acta 439: 231-250. doi:10 .1016/j.cca.2014.10.017

Niemz A, Ferguson TM, Boyle DS. 2011. Point-of-care nucleic acid testing for infectious diseases. Trends Biotechnol 29: 240-250. doi:10.1016/j.tibtech.2011.01.007

Nolan T, Hands RE, Bustin SA. 2006. Quantification of mRNA using real-time RT-PCR. Nat Protoc 1: 1559-1582. doi:10.1038/nprot .2006 .236

Notomi T, Okayama H, Masubuchi H, Yonekawa T, Watanabe K, Amino N, Hase T. 2000. Loop-mediated isothermal amplification of DNA. Nucleic Acids Res 28: e63. doi:10.1093/nar/28.12 .$e 63$

Piepenburg O, Williams CH, Stemple DL, Armes NA. 2006. DNA detection using recombination proteins. PLoS Biol 4: e204. doi:10.1371/journal.pbio.0040204

Ramamurthy T, Ghosh A, Pazhani GP, Shinoda S. 2014. Current perspectives on viable but non-culturable (VBNC) pathogenic bacteria. Front Public Health 2: 103. doi:10.3389/fpubh.2014 .00103

Saiki RK, Scharf S, Faloona F, Mullis KB, Horn GT, Erlich HA, Arnheim N. 1985. Enzymatic amplification of $\beta$-globin genomic sequences and restriction site analysis for diagnosis of sickle cell anemia. Science 230: 1350-1354. doi:10.1126/science .2999980

Sando S, Narita A, Hayami M, Aoyama Y. 2008. Transcription monitoring using fused RNA with a dye-binding light-up aptamer as a tag: a blue fluorescent RNA. Chem Commun 3858-3860. doi:10.1039/ b808449a

Shi J, Gao X, Tian T, Yu Z, Gao B, Wen A, You L, Chang S, Zhang X, Zhang $Y$, et al. 2019. Structural basis of Q-dependent transcription antitermination. Nat Commun 10: 2925. doi:10.1038/s41467-01910958-8

Trachman RJ, Autour A, Jeng SCY, Abdolahzadeh A, Andreoni A, Cojocaru R, Garipov R, Dolgosheina EV, Knutson JR, Ryckelynck M, 
et al. 2019. Structure and functional reselection of the Mango-III fluorogenic RNA aptamer. Nat Chem Biol 15: 472. doi:10.1038/ s41589-019-0267-9

Velusamy V, Arshak K, Korostynska O, Oliwa K, Adley C. 2010. An overview of foodborne pathogen detection: in the perspective of biosensors. Biotechnol Adv 28: 232-254. doi:10.1016/j .biotechadv.2009.12.004

Vincent M, Xu Y, Kong H. 2004. Helicase-dependent isothermal DNA amplification. EMBO Rep 5: 795-800. doi:10.1038/sj.embor .7400200

Wang S, Lifson MA, Inci F, Liang L-G, Sheng Y-F, Demirci U. 2016. Advances in addressing technical challenges of point-of-care di- agnostics in resource-limited settings. Expert Rev Mol Diagn 16: 449-459. doi:10.1586/14737159.2016.1142877

Yaseen IM, Ang QR, Unrau PJ. 2019. Fluorescent visualization of mango-tagged RNA in polyacrylamide gels via a poststaining method. J Vis Exp e59112. doi:10.3791/59112. doi:10.3791/ 59112

Zhao X, Lin C-W, Wang J, Oh DH. 2014. Advances in rapid detection methods for foodborne pathogens. J Microbiol Biotechnol 24: 297-312. doi:10.4014/jmb.1310.10013

Zhao Y, Chen F, Li Q, Wang L, Fan C. 2015. Isothermal amplification of nucleic acids. Chem Rev 115: 12491-12545. doi:10.1021/acs .chemrev.5b00428 

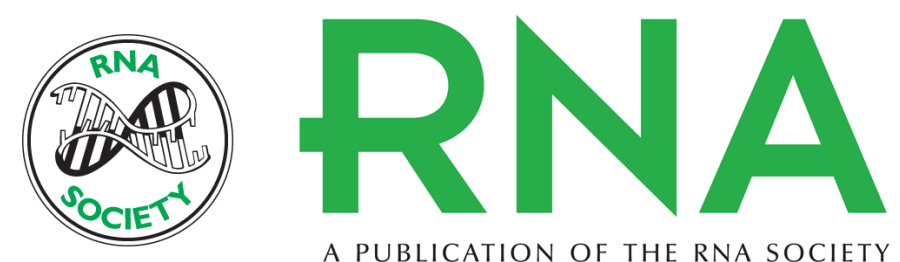

A PUBLICATION OF THE RNA SOCIETY

\section{RNA detection with high specificity and sensitivity using nested fluorogenic Mango NASBA}

Amir Abdolahzadeh, Elena V. Dolgosheina and Peter J. Unrau

RNA 2019 25: 1806-1813 originally published online September 24, 2019

Access the most recent version at doi:10.1261/rna.072629.119

\section{Supplemental Material}

References

Creative Commons License

Email Alerting
Service
http://rnajournal.cshlp.org/content/suppl/2019/09/24/rna.072629.119.DC1

This article cites 32 articles, 4 of which can be accessed free at: http://rnajournal.cshlp.org/content/25/12/1806.full.html\#ref-list-1

This article is distributed exclusively by the RNA Society for the first 12 months after the full-issue publication date (see http://rnajournal.cshlp.org/site/misc/terms.xhtml). After 12 months, it is available under a Creative Commons License (Attribution-NonCommercial 4.0 International), as described at http://creativecommons.org/licenses/by-nc/4.0/.

Receive free email alerts when new articles cite this article - sign up in the box at the top right corner of the article or click here.

To subscribe to $R N A$ go to:

http://rnajournal.cshlp.org/subscriptions 